\title{
Singlehood as an unscheduled status passage
}

In the Introduction, I wrote about an encounter with a colleague, during which she asked me how it was that a woman like me was still single. The presumption must be that this question wouldn't have been asked if I had been in my early twenties or late forties. But as a thirty-year-old woman at that time, her question was infused with a sense of urgency, and the hope that my single status would soon transform into a married one. It is worth paying attention to the expected temporal status passages that underpin interactions such as this. Precisely because these matters are rarely problematized, they warrant closer attention. In this chapter, I explore this transition as a social construct, and explore the various ways by which the status is produced and maintained through situated social norms and regulated temporal codes. To expand this analysis, I draw on sociological and anthropological studies, as well as considering my findings in relation to symbolic interaction traditions.

This chapter expands the analysis of the expected linear life-course trajectory as discussed in the previous chapter, but from a different perspective. The focus here is a conceptual analysis of becoming single, through which I explore the discursive mechanisms and regulations that generally shape it as a biographical disruption. In the chapter, I argue that this process is undertheorized in relation to singlehood, and its temporal assumptions rarely critically examined. Timely status transitions are configured as part of a default life trajectory subjected to socio-temporal schedules. As Zerubavel (1981) stresses, schedules are responsible for the establishment and maintenance of temporal regularity in our daily lives. It is these temporal regularities that I wish to observe, casting a critical light on how and why they are taken for granted.

My discussion examines this path in relational terms, through which the process of becoming single and the transition from "normative" to "late" singlehood is produced by socio-temporal truth statements. Thus, the stages of singlehood-or more specifically what I term as singlehood career, drawing on Goffman's use of the term-come into existence through a hegemonic temporal gaze. Throughout this chapter, I show how this gaze is established through social interaction, and is deeply ingrained in collective socio-temporal perceptions. Following this line of inquiry, I consider how the discursive switch of becoming single operates as a subtle non-institutionalized 
transition process, one through which the entry and exit from "normative singlehood" to "late singlehood" occurs without rituals or official formalities to accompany the change.

The second part of this chapter offers a temporal reading of the question "Why is she still single?," a question that many single women repeatedly hear and ask of themselves. My intent here is to explain the discursive formations and implications of this ubiquitous question, and to shed light on how popular knowledge about single women is produced and circulated. Thus, instead of asking why single women are single, I study how the inquiry is discursively constructed in relation to how singlehood, as I term it, is established. I view this process as an interpellative process, following Louis Althusser (1971), in which the woman as a subject is urged to respond. When single women ask themselves this question, they internalize the cultural stereotype that exists of themselves, as single women. However, as will be shown, single women find ways to subvert this question and the power of this dominant discourse.

\section{Charting the single life-course}

I begin my analysis with Louise (a pseudonym), regular contributor to Ynet, who outlines the following definition of the single-life-course trajectory:

18-23: Too young to be looking for something serious.

23-27: She is just too successful.

27-29: She is too picky, she will end up alone.

29-32: She is just too lazy. "Would it kill her to go out on the blind date her father set

up? So what if he doesn't know the guy, he knows his parents. It is a good family."

32-35: She has given up. What a pity. She used to be so beautiful. (Louise 2007)

This diagram is an excellent departure point for our exploration of how perceptions about single women's life trajectories cannot be isolated from contemporary temporal orders. In that sense, single women's temporal locations are not fixed or static categories, but rather ever-changing. It is interesting to observe the social mechanisms through which the reasoning of singlehood is subsumed. Thus, the proposed line of inquiry here highlights the socially situated aspects of the single woman's life trajectory. Louise demonstrates that under this collective temporal gaze, single women are objectified according to age-based evaluations: they fluctuate from being too young to becoming too old, picky, or lazy, until they cease to be suitably competent to participate in the search for a male partner.

The different life stages illustrate the elasticity of social definitions, and how social boundaries and categories are constantly created and subjected to arbitrary changes. Accordingly, each temporal phase determines the attributes and market value of single women. For example, between the ages of twenty-three and twenty-seven they are considered as "too successful," while between twenty-seven and twenty-nine they are "too picky." In this manner, Louise provides insightful commentary on how social mechanisms invent and configure social categories and boundaries. These expectations turn into constant self-surveillance, through which single women are expected to 
carefully monitor their life-course phases and police themselves according to the ensuing expectations.

One way to understand the discursive construction of the single woman's life trajectory is through the term status passage, coined by Barney Glaser and Anselm Strauss (1971). Their study differentiated between charted, planned, regularized passages and emergent passages, which are open-ended and are constituted as they occur. My claim is that this kind of differentiation can present a rich observational perspective regarding the changes in relation to single women's social status along the life course.

For this reason, I find Glaser and Strauss's analytical framework particularly useful, as it assists us in exploring the micro-status transitions which are over-simplified and rarely problematized. A more nuanced understanding of these transitions can reveal more about how they are determined by the disciplinary gaze of others; a critique of this gaze can present new opportunities for imagining alternative, more heterogeneous pathways. I wish to argue that one of the challenges of theorizing singlehood is the unarticulated entry and exit rites that define it. Unlike conventional perceptions of marriage and parenthood, there is a less agreed upon, visible, and tangible entry point to the stage at which midlife or late singlehood begins. As opposed to, for example, the still increasingly popular bachelor and bachelorette parties - which designate a clear exit and passage designating movement from one status to another-no such rituals or ceremonies are available for single women. ${ }^{1}$ Drawing on the work of Glaser and Strauss I term late singlehood as a non-scheduled status passage, as late singlehood has no institutional schedules of its own. Building on Zerubavel's (1981) formulation, this represents a temporal irregularity.

An example of a disruption of these expectations can be found in a Ynet column by Harela Yishi (2013) entitled "From the Queen of the Class to a Forty-Year-Old Single Woman: How Did It Happen?” Yishi, a relationship advisor, claims that at a certain phase in their lives, all single women who believed that "they had it all" end up on their own, alone. The illustration chosen to accompany the column depicted a woman sitting by herself on a beach with an empty chair next to her. The image was accompanied by a telling quote: "I thought I had all the time in the world, but then I remained alone." In common with Louise (2007), the single woman thought she had all the time in the world but lost her agentic capacity for time. The image of the solitary woman may also signify this involuntary "progression," or some kind of downward mobility associated with the image of the lonely single woman. Moreover, the question "How did this happen?" also marks a disruption to the sense-making mechanisms which are also embedded in the "Why is she single?" query, which I will return to in the second part of this chapter.

Helen Ebaugh's work (1988) on role exits draws upon Glaser and Strauss's research, and suggests that emergent passages are characterized by fewer precedent guidelines to facilitate the passage. Ebaugh also differentiates between role exits which are clearly defined by society — such as the retired worker or medical student-and non-planned passages - which are far less institutionalized - such as nuns who leave their religious orders (ibid., 155). Building on these lines of inquiry, I suggest that long-term 
singlehood could also be understood as a non-scheduled status passage. My point here is that exiting the normative singlehood phase and entering the late singlehood phase often lacks the structured expectations, rites of passage, and institutionalized socialization processes that are associated with moving in together, getting married, or having children, to state a few examples. It does not have a discernible time-related benchmark, nor is it identified by practices, symbols, or objects.

It might be that the expectation is that this elusive, yet vivid formulation would provide the answer to a question I have often encountered during my research on single women: When exactly does late singlehood begin? Friends, colleagues, students, and strangers have repeatedly posed this question, as though the question can be answered definitively. Might it be twenty-six, thirty, thirty-two, thirty-five? The answer varies, obviously, from one single to another, yet it is possible to sketch a more or less social timeline according to which the transition can be expected to take place. This could be further complicated by looking at these points of transitions as the different phases of the single woman's career, to borrow Goffman's (1961) well-known formulation. Goffman developed the concept of career to explain social transitions in everyday life and not only in occupational terms.

In Goffman's celebrated work on asylums, he referred to the moral career of patients as the progression of individuals through a number of social roles that position them as mental patients, as well as the way in which a circle of agents participate in the individual's transition from a civilian to a patient (ibid.). ${ }^{2}$ The aforementioned column (Louise 2007), when considered in light of Goffman's observations, draws our attention to the various ways in which female singlehood is interactional and socially accomplished. The sort of analysis suggested here understands singlehood as a process that is made and negotiated, and not as a stable social entity. In it, meanings of singlehood can be varied by differentiating the features that are themselves socially constructed and altered; in this specific case, differentiating the age cohorts and life stages of single women. Recognizing the constructed nature of the life-course highlights how singlehood is mediated by the meanings we attach to different life-course phases, and their expected transitions.

\section{In between status lost and status gained}

In her study on divorce, Nicky Hart (1976) offers a nuanced look at the process of marital breakdown. Hart argues that during the process of divorce, there is no precise point at which a person feels the complete disassociation from one's former life partner.

Being divorced is better thought of as becoming something than as occupying a fixed social position with well demarcated boundaries in time ... Passage from one status to another is rarely a clear-cut process. The status change may be marked by a ritual act and by an abrupt change of title or behavior. But in most cases the boundary between status lost and status gained is blurred; not only is the new status often partially experienced before the public rites of passage but also the life associated with the old status may never be completely discarded. (ibid., 103-104) 
In contrast to marriage, the entry point or transition to late singlehood in some ways resembles Hart's perception of divorce, in that the transitions in the single woman's life course seem more subtle and less concrete. In that way, the boundaries are less well-defined, and the passage indeed is not a clear cut process. Still, in common with other religions and civic cultures, divorce in Judaism is ritualized and replete with sets of temporal symbols which accordingly mark time and bestow it with meanings and values.

Against this, I contend that the change of status - namely transitioning from a "young single woman," or being associated with what is perceived as normative singlehood phase, to becoming "a woman who has passed her prime"-is not an abrupt, straightforward transition but rather an unstructured and unscheduled one. It can be perceived as a private, invisible and subtle process, but at the same time it is highly visible. The blurred temporal boundaries that result can be one of the reasons why entering the late singlehood phase leads to so much confusion and heightened anxiety. The process of becoming a single woman and the different unstructured phases of singlehood lack the sense-making devices, role expectations, and orientation rules which formal rituals supply.

This dynamic was beautifully exemplified in a conversation I had some years ago with my cousin, who was eight years old at the time. While discussing the advantages and disadvantages of single life, she asked whether her eighteen-year-old sister could be considered to be a single woman. Her question poignantly illuminated the subtle process by which one becomes single. It is perhaps the case, then, that singlehood becomes a tangible and visible category only when marriage and family life appear on the life-course trajectory as a concrete option. One is much less likely to ask a sixteenyear-old girl if she is single or married than a thirty-five-year-old woman.

Hazan observed a similar lack of rites of passage at a day center for elderly people in London:

There is no element of preparing the participants to enter a new phase in their lives ...

There are no official instructors, no official novices, no recognized stages through which participants pass, and no social recognition of the conversion. (Hazan 1980, 147)

In some respects, the same sentiment could be applied to single women. There are no preparatory processes, no official instructors, and no novices. In everyday talk, we often refer to the idea of becoming single after experiencing a visible transition point such as separation, divorce, or widowhood. Self-help books like Becoming Single: How to Survive When a Relationship Ends (Keith and Bradley 1991) stress how divorce can operate as a de-coupling process, marking a new social phase in one's life trajectory. This kind of guidance and advice, as offered by such self-help books, seeks to help individuals negotiate this transition.

The unexpected change of status in the case of late singlehood requires different sorts of social learning and heightened reflexivity. For example, Lalli Blue, a single woman and Ynet columnist, observes: "My status as a single woman is a total fact. I have learned to look into the glass and to see the wine, to see the good things" (Blue 2006). This passage acknowledges that the transition into a late single woman involves 
a process of social learning. Unlike marriage and family life, social life does not prepare one for late singlehood; there is no recognized or institutionalized process of socialization for such a status. No one hears of an adult preparing a child "for the rigors and requirements of late singlehood," primarily because this stage is not granted the social legitimacy accorded to other statuses. Indeed, the very idea sounds absurd. It is not a given self-evident process, but rather demands personal and social re-adjustments, both by single women and their environments, and a temporal re-orientation is one of these. The need to readjust stems also from the absence of positive models for longterm singlehood, and no preparation or socialization for this life path.

The desire of single women to get married within a few years or very soon dictates planned future pathways. Under these discursive conditions, wishing for a young man or woman to stay single is not an option; it might be interpreted as an insult or even a curse. The "old maid" cannot serve as a role model (and there are hardly any "positive" options that involve lifelong singlehood); consequently, the possibility that one might become such a relic is not even discussed.

The common understanding of singlehood is of a transitory and preparatory phase. During this time, one ought to prepare for married life. This unfeasibility of discursively structuring the single status further accentuates its prescribed emptiness, incoherence, and lack of meaning. My contention here is that there are strong links between the absence of positive models of late singlehood, and the lack of a structured transitioning process to the configuration of late singlehood as a disruption.

\section{"Late singlehood" as a disruption}

The idea of "late singlehood" disrupts the cultural expectations about life-course schedules. An analysis of the various texts discussed thus far illustrates the manner in which this disruption is experienced, and highlights especially the gaps between cultural norms and the subjective experiences of single women. The term "late singlehood" in itself represents a disruption and, as such, a disparity. In other words it commonly represents an unjustified delay which "has gone too far." In certain ways, the unstructured transition into lifelong singlehood indicates a separation from collective timetables and societal rhythms without re-integration to new ones. What emerges from many of the texts examined in this book is that many single women, from a certain point in time, are perceived as disoriented, marginal subjects.

This experience of temporal a-synchronization is one of the reoccurring experiences among many single women. It is manifested, for example in the questions that single women are asked again and again, e.g. "When are you going to get married?" In the texts analyzed throughout this study, marriage and family life are still very much considered as the natural, required steps that align with the dominant norms that signify maturity and success. This vision is reflected in the next passage:

When we were young, the only reason to fear the holiday dinner was the food ... The same dinner for single women who have passed the age of twenty-seven can be experienced as a military exercise in jumping through flaming hoops ... In a world where marriage is considered to be worthy of a Nobel Prize ... the single daughter, the single 
grandchild, and the single niece are considered to be failures while all of the other women in the family hold the prize [of marriage]. (Thelma and Louise 2006 $\mathrm{a}^{3}$ )

For the writers in question, the point of transition comes at the age of twenty-seven. A clear hierarchy is erected, once again, between the singles and non-singles sharing the same dinner table. Here, I wish to argue that late singlehood is not granted with the symbolic privileges and profits associated with the nuclear model. As Pierre Bourdieu notes, the family is:

a de facto privilege that implies a symbolic privilege - the privilege of being comme il faut, conforming to the norm and therefore enjoying a symbolic profit of normality ... The family plays a decisive role in the maintenance of the social order, through social as well as biological reproduction, i.e. reproduction of the structure of the social space and social relations. (Bourdieu 1993, 23)

Bourdieu's observation sheds light on what bestows this hierarchy with so much power and logic. My formulation of singlehood as an aberration to this normative temporal ordering is also indebted to Gay Becker's (1994) important scholarship on disrupted lives. Becker sees disruption as a multifaceted cultural process, one which enables reexamination of the disparity between cultural ideals "of how things are and how they actually are” (ibid., 401). As she explains elsewhere:

When expectations about the life course are not met, people experience inner chaos and disruption. Such disruptions represent loss of the future. Restoring order to life necessitates reworking the understanding of the self and the world, redefining the disruption and life itself. (Becker 1999, 4)

In a study of youth unemployment in Norway, Hogne Ÿian follows Gaston Bachelard's argument by stressing that lived time is not rooted in time as an a priori form or substance, because time is not an integrated or a one-dimensional continuity, but rather is discontinuous (Bachelard 2000 cited in Ÿian 2004, 181). In a study concerning unemployment in Austria, Marie Jahoda and Hans Zeisel (1974) contended, for instance, that leisure for the unemployed was a tragic gift, as for the unemployed the division of the day into hours had lost all meaning

Hence, the notion of continuity and sequence are a primary meaning-making device, sustaining the illusion of order against the backdrop of inherent disorder (Becker 1999). This point is also developed in Becker's study:

We fool ourselves into thinking that the world is an ordered place. That's how we get up in the morning and how we go to bed at night, because we are ordering the world in some fashion ... and it is just an illusion, an illusion that keeps us going. If we didn't pretend that that's the way it is we wouldn't be able to function. (ibid., 63)

Amongst the common threads linking these experiences are the complex temporal negotiations people undertake when they are distanced from the linear time path. This separation and even disorientation demonstrates a distancing from society's main institutions and sense-making mechanisms. Marginalized groups, such as the unemployed, prisoners, the homeless, or chronically ill persons, are symbolically 
removed from partaking in collective linear movements, as they "fail" to keep up with normative schedules.

Gerda Reith's (1999) research about the subjective aspects of time among drug addicts also shows how linear perceptions of development and progress are no longer relevant for many of her interviewees, which leads them into creating their own time. In various other studies on prisoners (Scarce 2002), the chronically ill (Charmaz 1997), and HIV patients (Davies 1997), researchers have illustrated the manner in which groups construe their own timeframes. Michele Davies, for example has attempted to understand how the diagnosis of and living with HIV among HIV patients has changed their orientation towards time and the ways in which they seek to compensate for the loss of the temporal assumptions that existed prior to the diagnosis. Davies has found that when a person receives a diagnosis of HIV, they are immediately taken aback by the certainty of the assumed futurity of their existence. Becker argues poignantly that when things are synchronized, time can go unnoticed, yet when it is disrupted it becomes visible.

These varied perspectives provide rich insight into how hegemonic perceptions of time establish normativity and stability, and accordingly produce "late singlehood" as an abnormality and a mistake to be fixed. This normative temporal discourse on singlehood devalues any disruption to the linear developmental life trajectory. This particular temporal experience can be seen as a biographical disruption reiterating Michael Bury's (1982) term. In his analysis of chronic illnesses, Bury analyzes how they disrupt daily lives and the knowledge associated with it. According to Bury, one is abruptly acquainted with experiences of suffering, pain, and death, which were previously seen as distant possibilities. His articulation of the idea of distant possibilities is also highly relevant for the cultural production of "late" singlehood. When the prevailing norm is that "By your wedding day you will feel better" or "Soon at yours [wedding]!" life long singlehood is rarely expected. As Hazan notes:

The social patterning of time, which originates in the inability to conceptualize a continuous flow of change, may take various forms. Cultural codes breaking up time into symbolically recognizable units serve to make sense of experience. When these codes lose their social validity or cease to reflect experience, temporal construction collapses. (Hazan 1994, 74)

Lifelong singlehood is not a possibility which can be imagined through the socialization process, and is not indicated in life-course charts and diagrams. However, as I will further elaborate in the last chapter of this book, there are new voices which present long-term singlehood as a viable and non-disruptive option, and accordingly view this option in terms of self-development and achievement. For example, a recent study conducted by two Canadian psychologists (Moore and Radtke 2015) found that some of the midlife single women they interviewed constructed their midlife as a time of transition, one in which, "following a period of critical self-examination, reevaluation, and action-taking - one aims to create a stable, economically secure, and satisfying life as a single woman" (ibid., 310). Moore and Radtke have termed this subject position "comfortably single at midlife women," as these women have accepted their single position as an independent and viable way of life. 
This finding stands in contrast to deficit subject position (Reynolds 2008), which emerges from the above mentioned Israeli columns in which the status passage to late singlehood requires a reassessment of one's position, as familiar sense-making devices are disrupted. This breakdown in the articulation of time is revealed and validated by some of the most disturbing sets of questions encountered by most late single women: Why are you still single? What's stopping you from getting married? However, instead of responding to this set of questions and accepting its heteronormative logic, I propose to explore the way it reflects temporal schemes and normative life trajectories.

\section{Why are you still single?}

Let's take for example Ella, a thirty-four-year-old woman ... beautiful, witty, intelligent, and funny. Apparently no one can understand why she is alone. (Brodsky-Kauffman 2008a)

Ayelet ... is a thirty-four-year-old woman, a beautiful and attractive woman. She has an MBA and holds a senior position in a big company. She belongs to a middle-class family but she has never been in a long-term relationship ... She knows how to flirt; she keeps her eyes wide open and recognizes what she has in front of her. Nonetheless, she struggles to understand how it can be that despite all of her wonderful features, she is still alone. (Brodsky-Kauffman 2007a)

The excerpts above were penned by Esta Brodsky-Kauffman, a dating advisor. Many of Esta's columns, published on the Israeli portal $\mathrm{nrg}$, deal with what she refers to as a new social problem: the thirty-something, good looking, intelligent, successful, yet still single woman. In this part of this chapter I offer a temporal reading of this question so prevalent in discursive patterns about single women. My intent here is to comprehend its discursive formations and to discern how these regimes of truth exclude other forms of knowledge.

Most commonly, this question is expressed with more than a touch of surprise. It first sets out to understand "what went wrong," and secondly seeks to uncover the hidden reason(s) for one's late singlehood. This question is often raised by singles themselves: "Why am I single; what is wrong with me?" These questions and selfdoubts emerge as pervasive disciplinary apparatuses (Foucault 1991), that can be asked by anyone at any time. Sociologist Margaret Adams proposes turning the tables:

Confront a happily married woman with the same question: what happened, Martha, Eleanor, Patricia ... that you got married? ... tendered in a tone of voice suggesting that an explanation is clearly needed to allay my incredulousness at such an apparently strange measure. The reaction [would be] fascinating and illuminating. (Adams 1976, 264)

Indeed, in most cases where couples decide to get married, it is more likely that they will be asked when and where, rather than why. This highly ritualized pattern of social interaction yields almost automatic enthusiastic blessings. Asking a couple why they have decided to marry would appear illogical and inappropriate, and would clearly violate conventional behavioral norms and standards of politeness. This predictable 
encounter includes a well-established social scenario, normative expectations and etiquette norms. Raising this kind of question, as Adams suggests, is considered to be bad manners and a transgression of etiquette rules.

The ongoing disbelief stressing the immense power of this cultural convention continues to mark single, thirty-something women as deficient and incompetent, as well as an object for interrogation, negative evaluation, and suspicion. Despite the prevalence of political correctness codes, the question appears to remain as socially legitimate as ever.

However, as daily interactions attest, such questions can be asked at any time. For years now, I have been asked again and again to justify my status as single and childless. It could happen anywhere: at a friend's wedding, in a cab on the way to the airport, or whilst awaiting my turn at the hairdresser's. In one particularly comic encounter, whilst speaking with three Italian sisters in a Venetian salon, all three raised their hands and shook their heads in disbelief: "Ma tu sei bella, tu sei bella!" (But you are so pretty!). I was thirty-nine- years- old at the time. As "late singlehood" is still perceived as a temporary and "unnatural" category, no efficient silencing system has thus far been developed which would de-legitimize such questions and no etiquette exists concerning what is appropriate to ask. The constant need to account for and justify one's singlehood and agency to control one's timeline is not limited to private social interactions.

One example that stands out especially took place a few years ago, during a press conference in Jerusalem with the American Secretary of State, Condoleezza Rice (Gearan 2007). During the event, Rice was asked about her status as a single woman. Specifically, she was asked whether being single might hinder her capacity to relate to the pain experienced by American families who had lost their loved ones in Iraq. Rice responded, somewhat bashfully, by observing that being single did not render her incapable of understanding American sacrifices in times of war. Following on, Tzipi Livni, Israeli Minister of Foreign Affairs at that time, declared (after first clarifying that she was married with children) that during informal conversations with Secretary Rice, the latter consistently expressed her deep sorrow over American losses in Iraq, and that the American public should know this.

This was not the first time Rice had been obliged to account for her single status. USA Today's reporting on the incident also revealed that at a previous function in the US Senate, Senator Barbara Boxer told Rice that "without an immediate family [she] will pay no personal price for the Bush administration's policy in Iraq” (ibid.). Later, Rice admitted that she was at first perplexed by the exchange, telling Fox News: "Gee, I thought single women had come further than that" (ibid.). These comments, particularity when pronounced by a progressive feminist politician such as Boxer, could be seen as another indicator of the extent to which critical thinking and feminist critique are ignorant of critical studies of singlehood.

In the Introduction, I referred to Garland-Thomson's work (2002, 2), which asserts that disability is still not an icon on many critical desktops: by paraphrasing GarlandThomson's observation, I have made a similar assertion about the relationship between singlehood and feminist theory and practice. Indeed, feminists have paid scant attention to the ways in which singlism constitutes a form of inequality, reflecting explicit 
and implicit forms of oppression. The incident with Rice, in common with so many other encounters unfolded throughout this book, reflects how singlism permeates our daily lives but remains rarely acknowledged as such, even in progressive circles. For instance, I believe that it would be far less appropriate, today, to inquire as to the reasons for a woman's sexual preferences on live television in Israel and many European and Anglo-American cultures.

These discursive patterns are often highlighted to an extreme in popular television shows, such as the Israeli versions of The Bachelor and Dating in the Dark from the UK, for example. Reynolds (2008) describes how in the television program Holly and Fearne Go Dating, broadcast in the UK, the two hosts approach passers-by and ask them "Why [they] think [they] are single?" (ibid., 123). As Reynolds clarifies, the show was based on the premise of scrutinizing the relationship history of the single person interviewed, while attempting to discern possible obstacles to the attainment of couplehood and family life. The context created by this reality show presents being single as a problematic state, one that can only be accounted for through personal mistakes and inappropriate conduct (ibid.).

These occurrences highlight the fact that it is still quite socially acceptable to treat singlehood as a legitimate target for suspicion, mockery, or even public humiliation. The press conference in Jerusalem revealed a fascinating cultural dynamic highly relevant to our analysis. What particularly captured my attention while watching this scene was the fact that singlehood, even when attached to such a public figure, remains a category that generates suspicion and demands explanation. Having a family, it appears, still provides many societies with important social signals about a person's constitution and moral character. In common social imagery, this status confers responsibility and credibility. No matter how ridiculous or flawed these assumptions may appear to be, they reflect deeply ingrained social understandings about sociality, collective timetables, and gendered respectability. Indeed, they are grounded in a long legacy of thinking, through which single women have been subjected to disproportionate scrutiny, exclusionary measures, and prejudicial beliefs regarding their character and civility.

These kinds of inquiries reflect, among other things, the social confusion that occurs when singlehood ceases to be a temporary stage. As noted before, singlehood is discursively framed as a liminal, temporary state; a transitory stage on the way to couplehood and family life. In his study on the ritual process, Victor Turner (1969), drawing on Arnold Van Gennep's (1960) theory of the three stages of rites of passage, placed particular emphasis on the second stage - the liminal stage, highlighting its fundamental social importance. Liminality, he emphasized, is a state of being between phases - a transitory state. The individual positioned in the liminal phase is neither a member of the group she previously belonged to, nor a member of the group she will belong to upon the completion of the next rite.

In similar fashion, lifelong singlehood marks an unexpected disruption, a normatively liminal state which has unexpectedly become a permanent one. This stage, as Turner (1969) notes, is also characterized by ambiguity and inversion resulting from an anomaly wherein people slip through networks of classifications. More specifically, 
singlehood at the age of eighteen or twenty-three is still located within the boundaries of the socially structured life course, whereas it would fall outside of this framework after a few short years.

I consider the ever repetitive question "Why is she still single?" as reflecting some of the dominant social temporal understandings of singlehood. At some point in the single woman's life trajectory, her singlehood shifts from being a socially legitimate temporary phase to what can be considered as a biographical and social disruption (Bury 1982). This leads us to some of the central questions in the present study: What are the discursive implications when singlehood ceases to be temporary and becomes a permanent status? Why is it almost impossible to imagine one's timeline beyond hegemonic heteronormative norms of reproductive linearity? Which discursive templates structure and cultivate these barriers? Likewise, why is it so difficult to conceptualize singlehood not merely as a liminal phase but as long-term life option? What happens when the expected passage to the next stage in a life-course structure is delayed or does not occur at all? And which discursive forces bestow these temporal truth claims with so much power, privilege, and universal normativity?

I view the question "why is she single?" then as a response to a transgression of socio-temporal boundaries reflecting the social confusion that occurs when singlehood ceases to be a temporary stage. One of the evident ramifications of this transgression is the need to provide explanations and justifications for this unexpected disruption. Interestingly, marriage, couplehood, and parenthood, according to common-sense knowledge, still serve as indicators of coherence, meaning, and moral order. These widely held beliefs also construe a particular kind of subjectivity.

Beyond the prevalent stereotypical labels attached to single women, they are depicted as leading empty, meaningless lives, and as lacking in moral competence and character. Not only are single women subject to increasing suspicion concerning their dubious moral trait, and not only do they "fail" to account satisfactorily for their singlehood, but their singlehood positions them as accountable to no one, and no one as accountable for them. This could also possibly explain why Boxer's critique of Rice did not trigger a media storm. I will continue to explore these threads in the next chapter by offering a critical reading of age, ageism, and singlism, as a potential source of invaluable insights to some of the taken-for-granted assumptions concerning temporality and singlehood.

\section{Notes}

1 For a rich analysis of the popularity of bachelor and bachelorette parties see Montemurro (2003, 2006); Tye and Powers (1998).

2 I draw on Goffman to stress, as he does, the "moral aspects of career - that is, the regular sequence of changes that career entails in the person's self and in his framework of imagery for judging himself and others" (Goffman 1972, 258).

3 The pseudonym of two single women columnists writing for Ynet. 